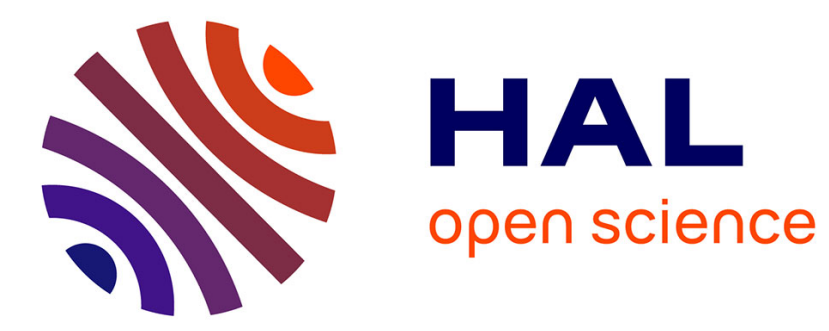

\title{
On some recent trends in modelling of contact fatigue and wear in rail
}

Ky Dang Van, Habibou Maitournam

\section{To cite this version:}

Ky Dang Van, Habibou Maitournam. On some recent trends in modelling of contact fatigue and wear in rail. Wear, 2002, 253, pp.219-227. 10.1016/S0043-1648(02)00104-7 . hal-00111361

\section{HAL Id: hal-00111361 \\ https://hal.science/hal-00111361}

Submitted on 23 Sep 2019

HAL is a multi-disciplinary open access archive for the deposit and dissemination of scientific research documents, whether they are published or not. The documents may come from teaching and research institutions in France or abroad, or from public or private research centers.
L'archive ouverte pluridisciplinaire HAL, est destinée au dépôt et à la diffusion de documents scientifiques de niveau recherche, publiés ou non, émanant des établissements d'enseignement et de recherche français ou étrangers, des laboratoires publics ou privés.

\section{다)(1) $(5$}

Distributed under a Creative Commons Attribution - NonCommercial| 4.0 International 


\title{
On some recent trends in modelling of contact fatigue and wear in rail
}

\author{
K. Dang Van*, M.H. Maitournam \\ Laboratoire de Mécanique des Solides (CNRS UMR 7649), Ecole Polytechnique, 91128 Palaiseau Cedex, France
}

\begin{abstract}
Specific numerical methods for the computational analysis of damage induced in rail by repeated rolling are presented. The calculations of mechanical stabilized states (shakedown, ratchetting) of rail-like structures subjected to moving contact loads are performed using the "stationary methods". An association of 2-D finite element method, Fourier expansion in the longitudinal direction of the rail and steady-state assumption reduces the computational cost of such procedures. These methods constitute the key for the quantitative prediction of fatigue. Three types of damage (low-, high-cycle fatigue and damage) are encountered. Special attention to high-cycle fatigue is paid, through the use of Dang Van multi-axial fatigue criterion. The 3-D simulations of rolling contact and investigation of rail high-cycle fatigue illustrate the applicability of the methodology.
\end{abstract}

Keywords: Multi-axial fatigue; Moving loads; Shakedown; Finite element analysis

\section{Introduction}

Rolling contact fatigue (RCF) is a severe problem for railways companies. Since many decades, the french national railways company SNCF had undertaken researches to understand the conditions of initiation of fatigue cracks which may appear in the rail head. These defects are of different nature, depending on the considered period of time. From the 1960 s to the early 1970s, the kidney-shape crackings are among the most frequently encountered defects on the track. They initiate in the rail head, at a depth quite far beneath the running surface (around $7 \mathrm{~mm}$ ) and propagate downwards in the rolling direction, in a plane making an angle of about $30^{\circ}$ relatively to the vertical. In some circumstances, especially on heavy loaded lines or on some curves, shelling can also be observed. It is associated with severe superficial plastic deformation. Nowadays, squats and head checks are the major defects which affect the rail. Squats are encountered on straight tracks or shallow curves. They initiate in deformed zones of the running surface. When these cracks reach a certain size (around $5 \mathrm{~mm}$ ) below the surface, they can propage downwards to form progressive transverse cracks which propagate quite fast. That is the reason why their prevention is necessary. Head checks are angle cracks observed on the high rail in curves

\footnotetext{
* Corresponding author. Tel.: +33-1-69-33-33-73; fax: +33-1-69-33-30-26.

E-mail addresses: dangvan@1ms.polytechnique.fr (K.D. Van), habibou@1ms.polytechnique.fr (M.H. Maitournam).
}

and on crossing rails. They iniatiate near the rail gauge corner and can join up to induce a gauge corner breaking. The reasons of this difference in the type of observed damages at these different periods are, on one hand, the nature of the rail steel (in the 1960s, the rail heads contained many inclusions due to the use of Thomas process steels) and, on the other hand, the increasing of load and power per axle.

To understand the circumstance of the occurence of these defects, researches have been undertaken in order to model their initiation. It is a complex problem which necessitates to overcome two main difficulties.

(i) The first one is the evaluation of the thermomechanical quantities in the rail induced by repeated rolling contact; because of the small size of the contact area, the stresses are beyond the elastic limit, so, it is necessary to take account of the plastic deformation and residual stresses resulting from the sequence of repeated rolling. Moreover, rolling contact is a 3-D problem with friction and complex partial slip. It is well-known that different limit states may be obtained depending on the intensity of the wheel load, the friction coefficient and the material properties. These limit states are: elastic state, elastic shakedown state (the limit cycle is elastic, but early plastic deformation induces a fixed residual stress pattern), plastic shakedown and ratchetting.

(ii) The second difficulty is the prediction of damage (this latter is closely linked to the mechanical limit state). This necessitates the use of multi-axial fatigue criteria able to deal with complex multi-axial loading situations. 


\begin{tabular}{|ll|}
\hline \multicolumn{2}{|l|}{ Nomenclature } \\
$a$ & half-contact width \\
$\boldsymbol{a}$ & constant of Dang Van criterion \\
& $\left(t_{-1}-\left(f_{-1} / 2\right)\right) /\left(f_{-1} / 3\right)$ \\
$\boldsymbol{A}_{k}$ & associated forces \\
$b$ & constant of Dang Van criterion $\left(t_{-1}\right)$ \\
$C$ & hardening modulus \\
$E$ & Young modulus \\
$f$ & yield function \\
$f_{-1}$ & alternate bending fatigue strength \\
$k_{\mathrm{e}}$ & shear yield stress \\
$\boldsymbol{L}$ & tensor of elastic coefficients \\
$p$ & microscopic hydrostatic pressure \\
$P$ & normal force \\
$P_{0}$ & maximum hertzian pressure \\
$Q$ & traction force \\
$t$ & time \\
$t_{-1}$ & alternate twisting fatigue strength \\
$\boldsymbol{u}$ & displacement vector \\
$\boldsymbol{V}$ & moving load velocity \\
$\boldsymbol{Z}$ & tensor relating $\boldsymbol{A}_{k}$ and $\boldsymbol{\alpha}_{k}$ \\
& \\
Greek & letters \\
$\boldsymbol{\alpha}_{k}$ & internal parameters \\
$\boldsymbol{\epsilon}$ & strain tensor \\
$\boldsymbol{\epsilon}^{\mathrm{e}}$ & elastic strain tensor \\
$\boldsymbol{\epsilon}$ & plastic strain tensor \\
$\Lambda$ & plastic multiplier \\
$\mu$ & local friction coefficient \\
$v$ & Poisson ratio \\
$\boldsymbol{\sigma}$ & stress tensor \\
$\boldsymbol{\sigma}_{0}$ & initial stress tensor \\
$\tau$ & microscopic Tresca shear stress \\
& \\
\hline
\end{tabular}

In fact the local stress and strain fields are completely tri-dimensional with no fixed directions during their evolution.

To solve the problem (i), we have developped powerful computational tools capable of determining the stabilized state of any kind of inelastic structures subjected to repeated moving loads, directly or by following the evolution pass-by-pass. The presentation of these numerical procedures can be found in [1-3], where they are validated by comparisons with analytical results obtained by Johnson [4,7,8], Bower and Johnson [5], Hearle and Johnson [6], Johnson and Jefferis [9]. Different applications to rail were presentated in [2].

For the problem (ii) we use, in the case of high-cycle fatigue, the multi-axial fatigue criterion proposed by Dang Van, of which fundations are presented, for instance, in [11-14]. Its main attribute is that it can be easily identified by classical fatigue uniaxial laboratory tests like repeated tension or torsion. This criterion is essentially based on elastic shakedown hypothesis at all scales of material description (macroscopic and mesoscopic scales). The Manson-Coffin law is considered in the case of low-cycle fatigue, especially for the prediction of shelling initiation.

The purpose of this paper is to present some main methods and computation procedures, and to show some new results we have obtained in the modelling of the different defects mentioned above. Finally, we insist more on the modelling of the defect named squat.

\section{Numerical methods for the determination of the limit thermomechanical state and fatigue}

\subsection{Presentation of the problem}

The determination of the thermomechanical fields induced by repeated rolling/sliding contact is the first step for the understanding and the prediction of fatigue damage phenomena which may occur in rail head. However, this task presents many difficulties due to load level which induces plastic deformation. The simulation of such processes by using classical existing finite element softwares necessitates incremental translations of the loading. This way of calculating (used in the late 1980s) is time-consuming and cumbersome. A simplified approach based on the proposal of Zarka et al. [15] was used by Sakae and Keer [16] and Keer and coworkers $[17,18]$, nevertheless, this approach used an approximate estimation of the plastic deformation. It is the reason why we have proposed another computing procedure for the evaluation of the thermomechanical state induced by repeated rolling contact. This method, valid for 2-D and 3-D problems, relies on the steady-state assumption in the moving contact reference. It leads to the two following numerical procedures for the calculations of stresses and strains either for an arbitrary number of loading passes or directly for the stabilized state (elastic shakedown, plastic shakedown or ratchetting): (i) the pass-by-pass stationary method (PPSM) for a single load pass; this method is exact and does not suffer from the limitations of previous rolling contact finite element analyse; the calculation time for one pass is approximatively the same as the one obtained in classical plasticity for one step of translation of the contact loading; (ii) the direct stationary method (DSM) for a repeated moving load, this method goes straight to the steady-state. These procedures were extended in the case of thermomechanical coupling realized by the presence of thermal expansion in the mechanical problem and of heat sources (due to inelastic deformation, thermoelastic coupling and interfacial dissipation mechanism, like friction and micro-slip) in the thermal problem [2]. They led to the evaluation of the temperature field in the vicinity of the contact area.

\subsection{Principle of the stationary methods}

The 'stationary methods' used in this paper to determine the mechanical state due to repeated rolling, and their finite 
elements implementation have already been published in $[1,2]$. Nevertheless, for the convenience, a summary of the main features of these methods is given below.

Consider a rail subjected to contacts loads (let us say normal and tangential pressures) moving with a velocity $\mathbf{V}$ $=\mathrm{V} \boldsymbol{e}_{z}$ (Fig. 1). Assuming steady-state in a reference frame moving with the loads, the time derivative of any material quantity $\boldsymbol{B}$ becomes:

$\dot{\boldsymbol{B}}=-V \boldsymbol{B}, z$

The first idea consists in writing the equations governing the mechanical problem in the moving loads reference. Thus, one obtains:

equations of motion

$\operatorname{div} \boldsymbol{\sigma}=\rho V^{2} \boldsymbol{u}, z z$

constitutive laws

$\boldsymbol{\sigma}=\boldsymbol{L}: \boldsymbol{\epsilon}^{\mathrm{e}}+\boldsymbol{\sigma}_{0}$

$\boldsymbol{A}_{k}=\boldsymbol{Z}: \boldsymbol{\alpha}_{k}$

$\epsilon=\epsilon^{\mathrm{e}}+\epsilon^{\mathrm{p}}$

$-\boldsymbol{\epsilon},{ }_{z}^{\mathrm{p}}=\Lambda \frac{\partial f}{\partial \boldsymbol{\sigma}} f\left(\boldsymbol{\sigma}, \boldsymbol{A}_{k}\right) \leq 0, \quad \Lambda \geq 0, \quad \Lambda f\left(\boldsymbol{\sigma}, \boldsymbol{A}_{k}\right)=0$

$\boldsymbol{\alpha}_{k, z}=\Lambda \frac{\partial f}{\partial \boldsymbol{A}_{k}}$

$\Lambda$ is the plastic multiplier, $f$ the yield function and the plastic potential ( $f=0$ defines the elastic domain), $\sigma_{0}$ the initial stress, $\boldsymbol{\alpha}_{k}$ are internal parameters and $\boldsymbol{A}_{k}$ their associated forces linked here by the tensor $\boldsymbol{Z}, \boldsymbol{L}$ is the fourth-order tensor of elastic coefficients.

Thanks to (Eq. (1)), time derivatives have been replaced by space derivatives in Eqs. (2), (6) and (7). The integrations of Eqs. (6) and (7) are performed in space, along the direction of the motion of the loads; so that, numerically neither the load, nor the structure are translated. Two kinds of material behaviour have been used for the rail: a von Mises elastic-plastic material with linear-kinematic and isotropic hardening of which yield function $f$ is given by:

$f\left(\sigma, C \epsilon^{\mathrm{p}}, \bar{\epsilon}^{\mathrm{p}}\right)=\sqrt{\frac{1}{2}\left(\sigma-C \epsilon^{\mathrm{p}}\right):\left(\sigma-C \epsilon^{\mathrm{p}}\right)}-k_{\mathrm{e}}\left(\bar{\epsilon}^{\mathrm{p}}\right)$

where $C$ is the hardening modulus, $k_{\mathrm{e}}$ is the shear yield stress, and $\bar{\epsilon}^{\mathrm{p}}$ is the cumulated plastic deformation, and the non-linear-kinematic hardening law proposed by Bower [10] to evaluate the ratchetting rate per cycle.

The second crucial feature of our methods is the direct numerical search of the possible stabilized mechanical state due to repeated rolling (the stress field is periodic, and the plastic strain also in the absence of ratchetting).

The two numerical procedures for the determination of the stabilized state are derived [1]. The first one is the PPSM for the calculation of a single pass. Computing the successive passes by this method, allows to find the stabilized state and its characteristics (number of cycles before reaching the stabilized state, residual stresses, plastic deformations, etc.). This stabilized state can, of course, be ratchetting. In such a case, the ratchetting rate is immediately deduced as the increment of surface displacement or plastic strains caused by a pass. The second one is the DSM for the direct determination of the stabilized state, in the case of shakedown (elastic or plastic). The ratchetting is indicated by a non-convergence of the algorithm.

\subsection{Solution methods}

These methods were programed using classical finite elements method in 2-D and 3-D. For the 3-D rail problem, in order to reduce the computational cost, it has been necessary to use a combination of a 2-D finite element analysis (in the section of the rail) and a Fourier expansion along the longitudinal direction of the rail (z-direction). The obtained solution is fully tri-dimensional. The displacement is expanded (so is the loading) in the following way:

$\boldsymbol{u}(x, y, z)=\sum_{n=0}^{N} \boldsymbol{u}_{n}^{c}(x, y) \cos \frac{n \pi z}{L}+\boldsymbol{u}_{n}^{s}(x, y) \sin \frac{n \pi z}{L}$

where the number $N$ is chosen sufficiently large to allow a good reconstruction of the input prescribed loading (contact stress distributions). Comparisons of shakedown limits given by numerical solutions and analytical ones in the case of an elastic-plastic half-space subjected to moving hertzian pressure, have also allowed us to validate the choice of $N$. $L$ is the length of the considered portion of the rail. It can be a distance between two contacts (two wheels).

The 3-D problem is solved iteratively, each iteration consisting in an elastic solution and a determination of plastic deformation (and internal variables). The Fourier expansion allows to reduce the elastic 3-D problem to a finite sum of 2-D finite element problems over a transverse section of the rail. Each 2-D problem is the calculation of a term $\boldsymbol{u}_{n}^{c}(x, y)$ or $\boldsymbol{u}_{n}^{s}(x, y)$ of the expansion. A re-combination of the displacements per harmonic is performed to obtain the total displacement. This latter is used to calculate the plastic deformation as in the preceding sub-section. The resulting plastic forces are then expanded for the elastic solution.

\subsection{Illustrative examples}

These methods allow the computation of strains and stresses in the rail due to repeated moving contacts and the quick determination of the nature of the stabilized state (elastic shakedown, plastic shakedown or ratchetting). Such analyses of repeated contacts using shakedown principles were carried out in 2-D [1,2] and compared with semi-analytical methods, by Johnson [4,7,8], Bower and Johnson [5], Hearle and Johnson [6], Johnson and Jefferis 


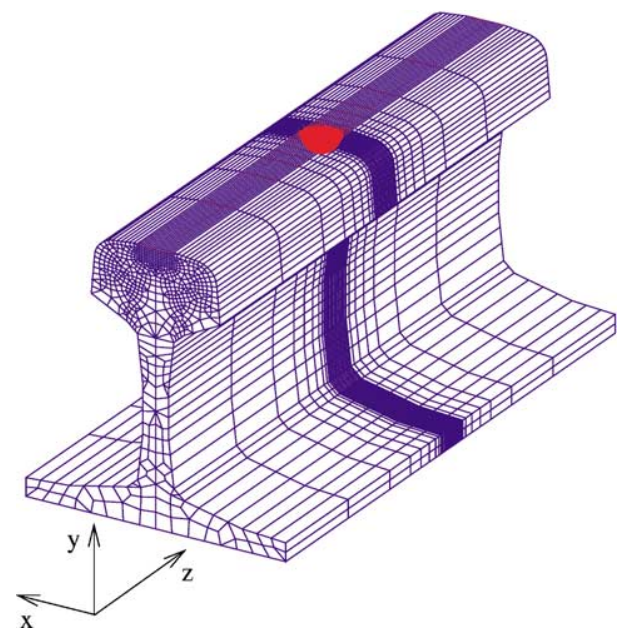

Fig. 1. An example of a rail mesh and a moving centered spherical pressure distribution.
[9]. We present below some 3-D calculations, to show the applicability of the method. The considered rail (UIC 60 profile) is as shown in Fig. 1. In full 3-D calculations the used mesh is the one on the figure. When using the method associating finite elements and Fourier expansion, only the mesh of a transverse section of the rail is used. The load is a repeatedly moving hertzian pressure (circular contact area with radius $a$, maximum hertzian pressure $P_{0}$ ). Dynamic effects are neglected. The characteristics of the considered material are: $E=210 \mathrm{GPa} ; v=0.3, k_{\mathrm{e}}=237 \mathrm{MPa}$; $C=20 \mathrm{GPa}$. Fig. 2 represents the equivalent plastic strain obtained during the first pass of the contact $\left(\mathrm{P}_{0} / k_{\mathrm{e}}=6.7\right.$; $a=10 \mathrm{~mm}$ and $2 a$ is the length of the refined zone). Fig. 3 represents the same quantity in the stabilized state which is obtained directly, without simulating the successive passes. One can see that this stabilized state is a plastic shakedown:

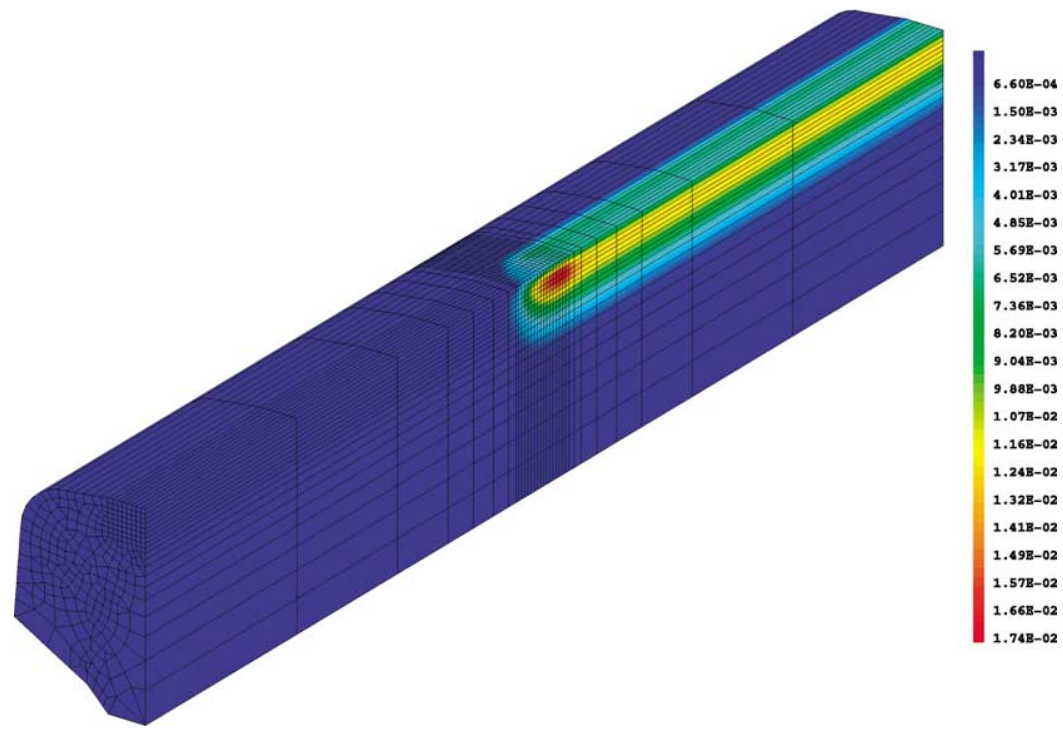

Fig. 2. Contours of equivalent plastic strains in the rail after one pass, for a spherical pressure distribution; $a=10 \mathrm{~mm} ; P_{0} / k_{\mathrm{e}}=6.7 ; \mu=0$.

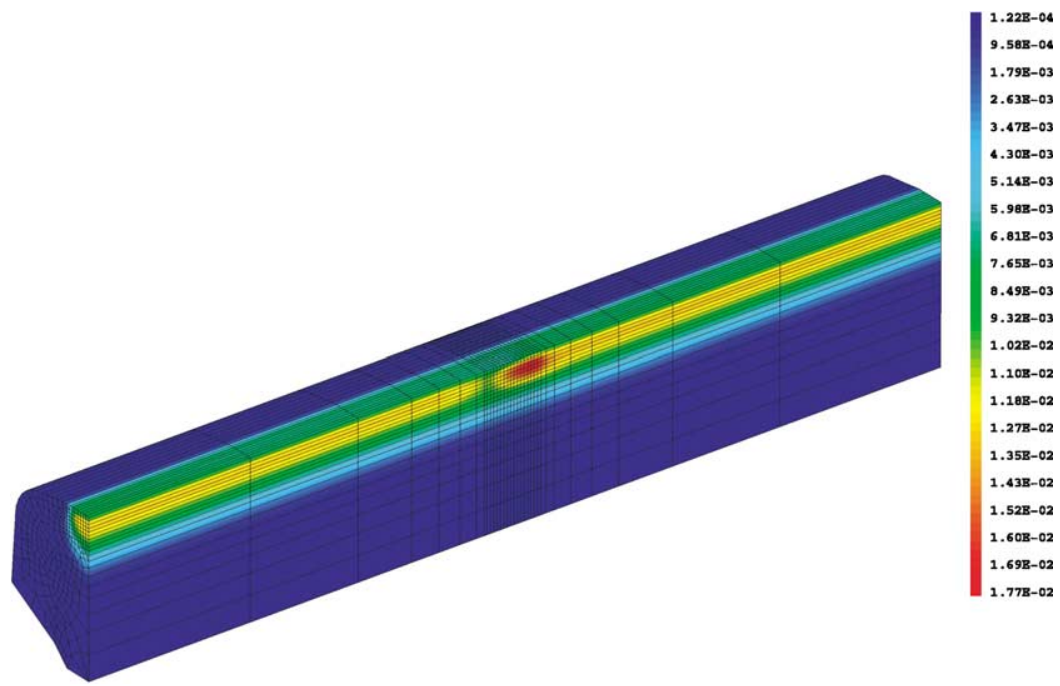

Fig. 3. Contours of equivalent plastic strains in the rail head at the stabilized state, for a spherical pressure distribution; $a=10 \mathrm{~mm} ; P_{0} / k_{\mathrm{e}}=6.7 ; \mu=0$. 
the plastic deformation is the same up- and down-stream of the contact but varies under the contact.

\section{Numerical methods for fatigue treatment}

Two kinds of fatigue criteria are used to predict crack initiation in the rail. When the rail suffers cyclic plasticity (plastic shakedown) or ratchetting low-cycle fatigue is likely to occur. For this kind of fatigue, we use the Manson-Coffin law to predict the number of cycle to crack initiation. In the case of elastic shakedown or elastic behaviour of the rail, high-cycle fatigue is likely to occur and Dang Van criterion [11-13] is used. The Dang Van multi-axial high-cycle fatigue criterion is based on a multi-scale approach which assumes that elastic shakedown happens before crack initiation. The considered two scales are: (i) a macroscopic scale characterized by an arbitrary elementary volume surrounding the point where fatigue analysis is made and representing for instance an element of finite element mesh (it is the usual scale considered by engineers); (ii) a mesoscopic scale corresponding to subdivision of the previous volume; the stress tensor at this scale results from the macroscopic one and the local residual stresses due to local inelastic deformation. Thanks to the shakedown assumption at the local scale, it is possible to estimate the local stress cycle from the macroscopic stress cycle. The criteria is then expressed as an inequality related to the mesoscopic stresses at all instants $t$ of the cycle, so that damaging load can be precisely characterized. The criterion used is expressed as:

$\max _{t}\{\tau(t)+a p(t)\} \leq b$

where $\tau(t)$ and $p(t)$ are the instantaneous mesoscopic shear stress and hydrostatic stress, $a$ and $b$ are material constants, which can be determined by two different classical fatigue

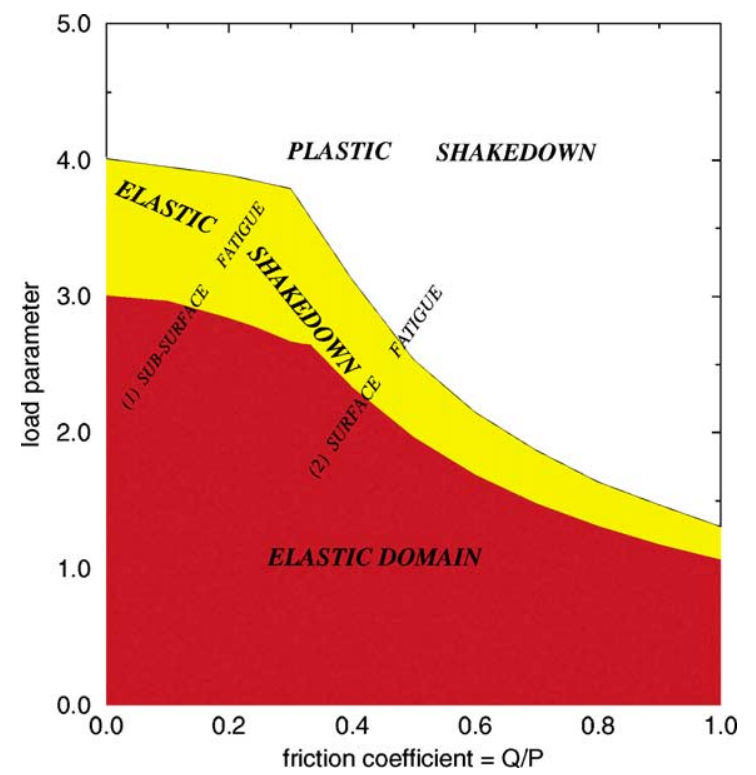

Fig. 4. Numerical shakedown and fatigue map for line contact and full sliding.

tests. For instance, they are related to classical experimental fatigue strengths $f_{-1}$ (in alternate bending) and $t_{-1}$ (in alternate twisting) by:

$\boldsymbol{a}=\frac{t_{-1}-\left(f_{-1} / 2\right)}{\left(f_{-1} / 3\right)}, \quad b=t_{-1}$

Practically, the fatigue resistance of a structure is checked point-by-point, using two ways:

- The first one is the representation of the loading path $(p(t), \tau(t))$ at each point in the $(p, \tau)$ diagram. In this diagram, two constants, $\boldsymbol{a}$ and $b$, define a safety domain (no fatigue cracks) which is the region below the line
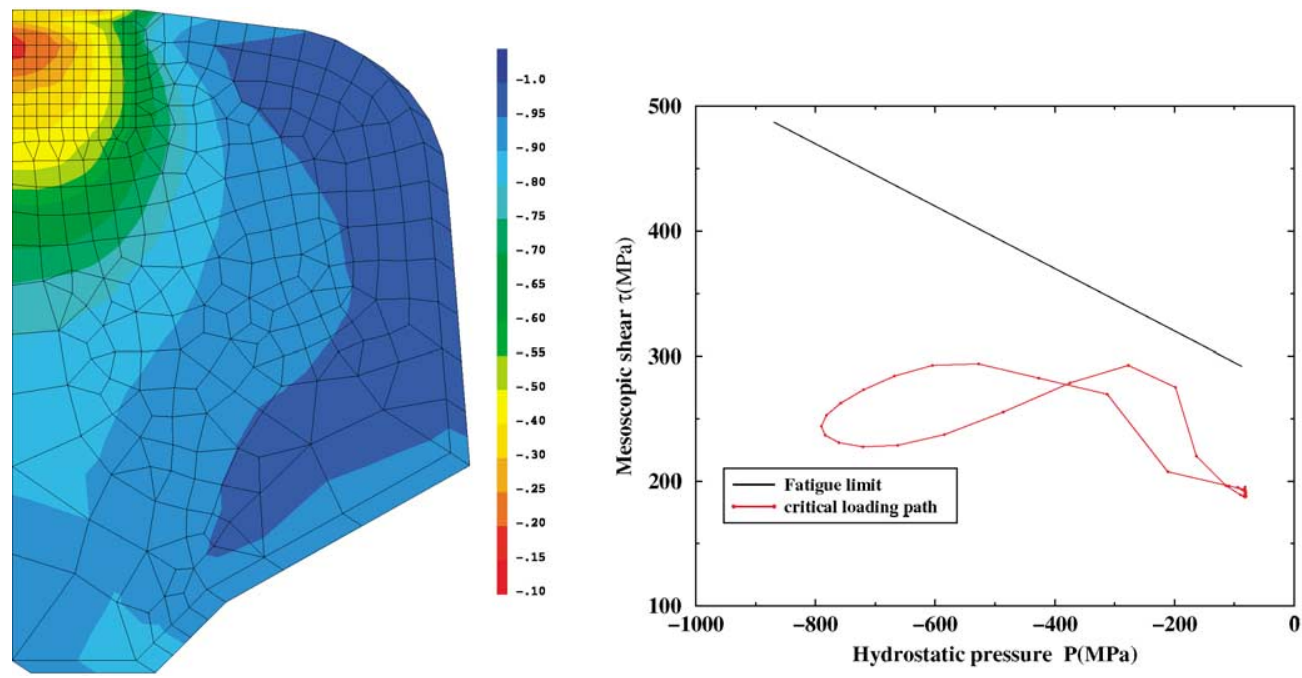

Fig. 5. Contours of Dang Van criterion $\left(\alpha=\max _{t}(\tau(t)-a p(t)-(b / b))\right)$ and loading path are the most critical point. 
$(\tau+a p=b)$. If the loading path at each point is entirely in the safety domain, there is no fatigue crack, otherwise fatigue damage occurs.

- The second one is the evaluation at each point of the quantity $\alpha=\max _{t}\{(\tau(t)+a p(t)-b) / b\}$. Positive value of $\alpha$ means occurrence of fatigue crack.

These two representations are used in the section devoted to numerical analysis of rolling contact to predict the high-cycle fatigue behaviour of rails. The predictions of kidney-shape crack, squat and head check are based on this criterion.

\section{Application to analysis of some rail damages}

\subsection{Kidney-shape cracking, shelling and wear}

The 2-D calculations were performed to evaluated the stabilized state and the residual stress pattern at different depths in the rail. By that way we obtained the local stress cycle for different conditions of traffic. Application of the adequate fatigue criterion allows to predict the locus of the crack initiation in relation with the load parameters. The methodology was presented in [2]. The results obtained are summarized in the fatigue map presented as shown in Fig. 4. This type

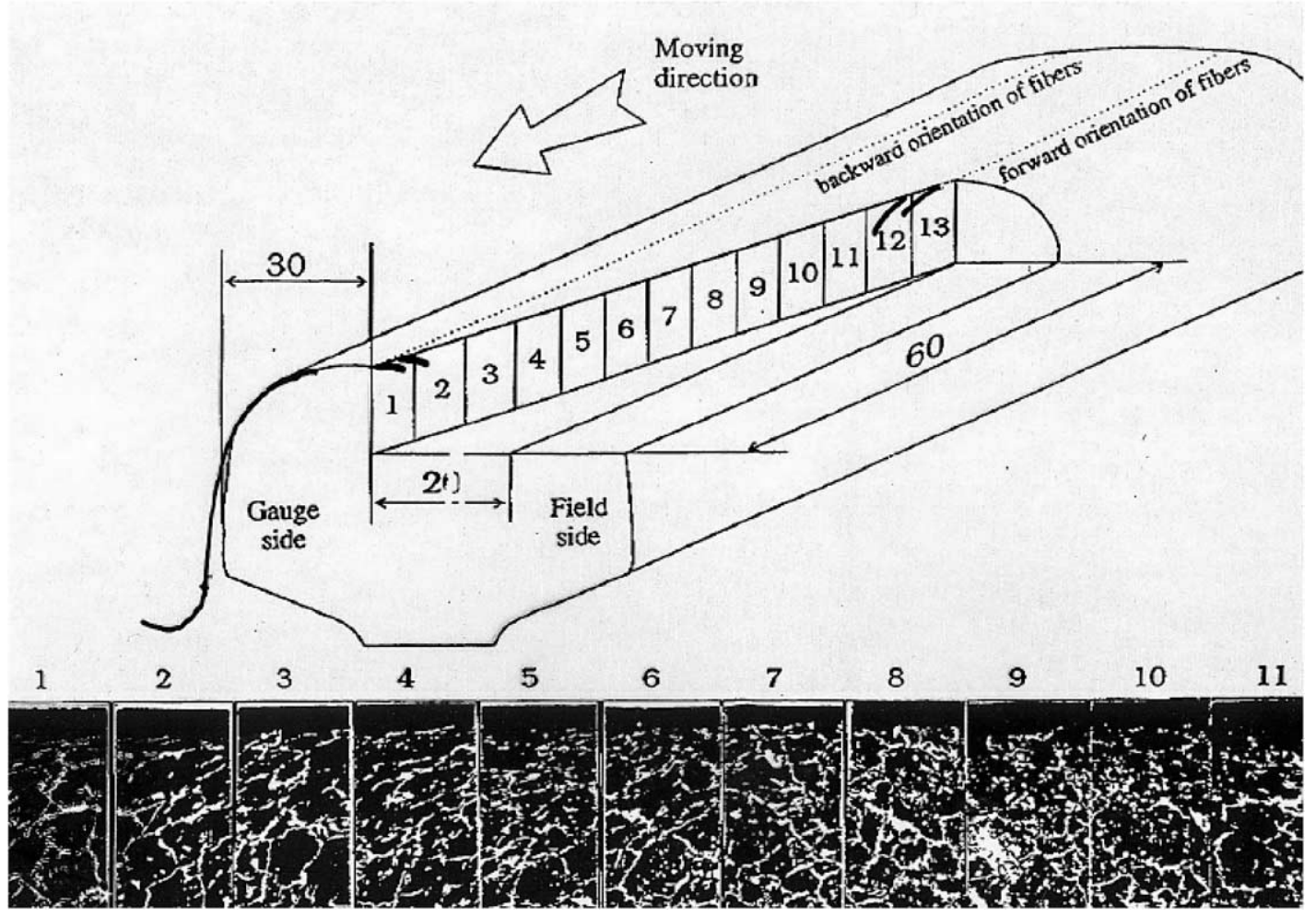

Fig. 6. Observations of the orientations of the fibers in the running zone (from IRSID): squat appears in the central zone.
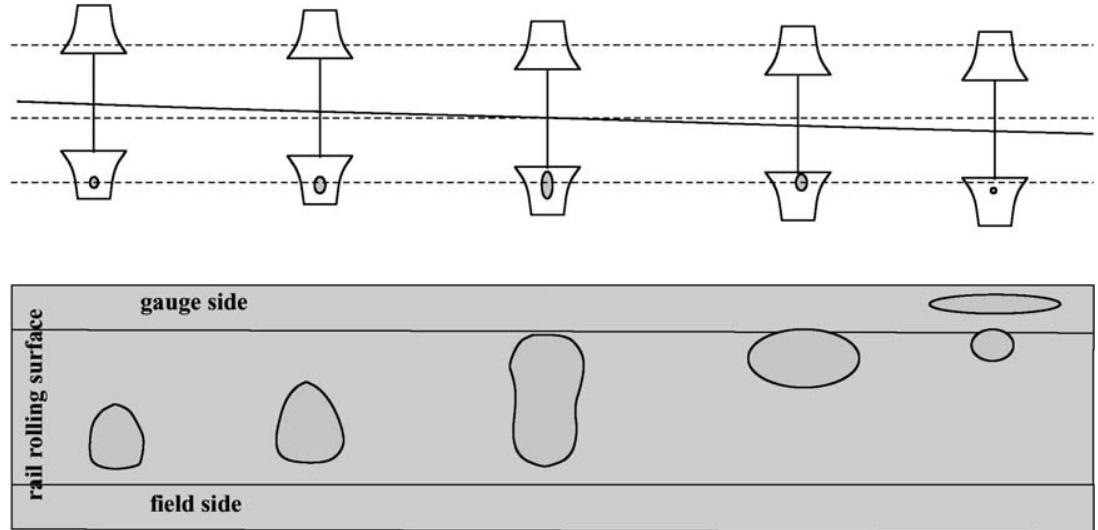

Fig. 7. An example of evolution of the contact area during dynamic movement of the wheel (re-simulated by INRETS as in [19]). 


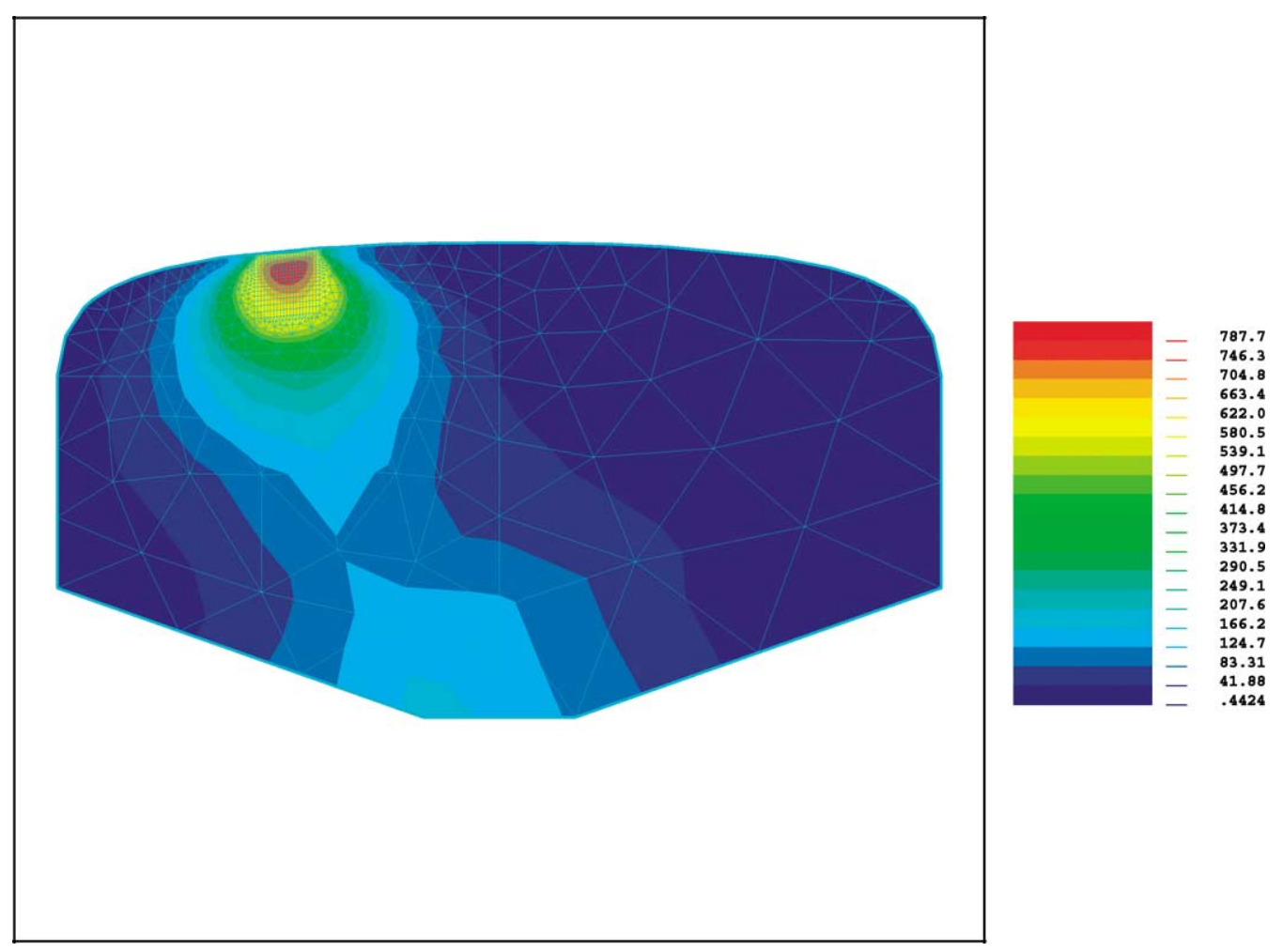

Fig. 8. Contours of von Mises equivalent stresses near the contact area, for the second pass of the loading.

of fatigue corresponds to the region (1) of the map: initiation in depth, high cycle fatigue in the elastic and elastic shakedown zones. The region (2) corresponds to the surface damage. When the plastic shakedown occurs (plastic deformation cycles), this regime leads shelling which is relevant to low cycle fatigue. In the case of high friction (braking zone) surface plastic flow may be severe, so that wear phenomena are predominant.

This methodology is now applied in the 3-D case. For illustration, we considerer the same structure and material as in Section 2.4. The moving load is characterized by $a=10 \mathrm{~mm}$ and $P_{0} / k_{\mathrm{e}}=4.25$. The fatigue limits of the rail steel are: $f_{-1}=460 \mathrm{MPa}$ and $t_{-1}=270 \mathrm{MPa}$. The stabilized mechanical state is an elastic shakedown. Fig. 5 shows the result of the application of the Dang Van multi-axial fatigue criterion: the most critical point is in depth, which is typical of kidney-shape crack initiation.

\subsection{Analysis of squat and head checking}

\subsubsection{The 3-D rolling contact problem}

The 2-D analysis fails in explaining the occurrence of squat cracking. In this case, the microscopic observations shows that superficial contact effects have to be taken into account. In Fig. 6 one can observe different fibers orientations (corresponding to severe local superficial plastic flow) depending on the position on the rail head surface and squat damage appears in a precise place. Dynamic computations of rail-wheel system performed by INRETS and based on Kalker method as in [19], shows complex evolutions of the rail-wheel contact with different shapes of the contact area, pressure and spin distributions. The contact area changes from one to two separate areas (Fig. 7). To simulate this phenomena, we choose a simplified scenario consisting in sequences of eight different passes of different contact loading. Each one corresponds to a particular position of the wheel on the rail. The contact stress distributions consist in normal pressure (maximum value is $1.6 \mathrm{GPa}$ ) and important tangential stresses (essentially resulting from spin effect, the value of which can reach $500 \mathrm{MPa}$ ).

\subsubsection{Evaluation of the mechanical state in the rail}

The 3-D numerical calculations using the PPSM presented in Section 2 are conducted. The method which combines Fourier expansion and finite elements is used. The mesh of the tranverse section of the rail can be seen in Fig. 8. The rail steel is considered as a von Mises elastic-plastic material with linear-kinematic hardening. The material constants are: $E=210 \mathrm{GPa} ; v=0.3 ; k_{\mathrm{e}}=550 \mathrm{MPa} ; C=20 \mathrm{GPa}$. A distribution of the stresses in the central rail section, after the pass of the second type of loading (elliptical distribution of the normal and tangential stresses due to spin effect and friction: Fig. 7, second from the right) is as shown in Fig. 8. 


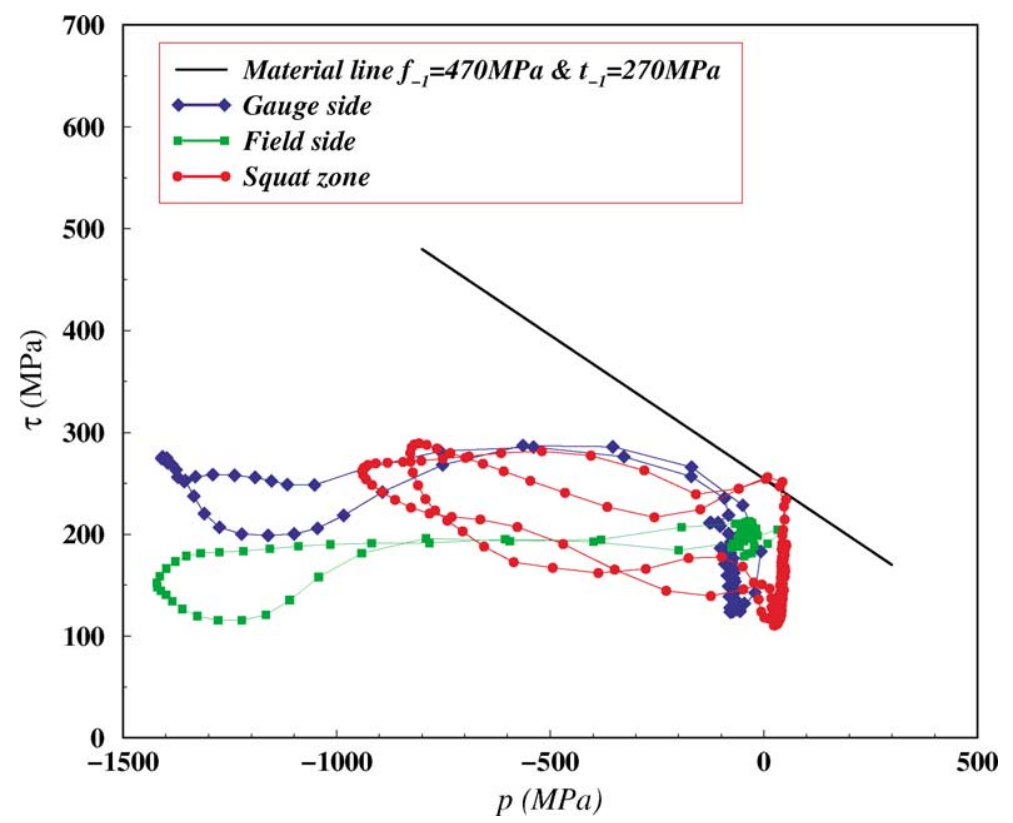

Fig. 9. Fatigue prediction: loading paths at different points of the rail surface.

\subsubsection{Fatigue prediction and comparison with observations}

Fatigue analysis is based on the use of the Dang Van multi-axial criterion. It was performed on and thanks to a specific fatigue analysis software. The fatigue limits of the used rail steel are: $f_{-1}=450 \mathrm{MPa}$ and $t_{-1}=270 \mathrm{MPa}$. The stresses are calculated at the stabilized state reached after passes of the contacts sequence described previously. The loading path at three different points (gauge side, central zone, field side) of the running surface are as shown in Fig. 9. It can be seen that fatigue cracks are likely to occur in the central zone.

\section{Conclusion}

We have developed specific numerical procedures allowing the determination of stresses and strains in the rail subjected repeated moving contacts, directly in the stabilized state or by following their evolution pass-by-pass. To show its flexibility, the 3-D simulations have been performed in the case of elastic-plastic material with a linear-kinematic hardening. By coupling this method with appropriate fatigue criteria, a good tool for the prediction of (high or low cycle) fatigue crack initiation can be obtained. The 2-D calculations have been sufficient to predict the kidney-shape cracks occurrence, but only the 3-D calculations give the main features of the apparition of squat.

\section{Acknowledgements}

The work has been partly supported by the SNCF. The authors are grateful to all the IDR2 partners, especially IRSID and INRETS.

\section{References}

[1] K. Dang Van, M.H. Maitournam, Steady-state flow in classical elastoplasticity: application to repeated rolling and sliding contact, J. Mech. Phys. Solids 41 (11) (1993) 1691-1710.

[2] K. Dang Van, M.H. Maitournam, B. Prasil, Elastoplastic analysis of repeated moving contact: application to railways damage phenomena, Wear 196 (1996) 77-81.

[3] K. Dang Van, M.H. Maitournam, Thermomechanical state near rolling contact area, in: D. Dowson, et al. (Ed.), Proceedings of the 20th Leeds-Lyon Symposium, Dissipative Processes in Tribology, Elsevier, Amsterdam, 1994, pp. 423-428.

[4] K.L. Johnson, The application of shakedown principles in rolling and sliding contact, Eur. J. Mech. Part A: Solids 11 (Special Issue) (1992) 155-172.

[5] A.F. Bower, K.L. Johnson, The influence of strain hardening on cumulative plastic deformation in rolling and sliding line contact, J. Mech. Phys. Solids 37 (4) (1989) 471-493.

[6] A.D. Hearle, K.L. Johnson, Cumulative plastic flow in rolling and sliding line contact, ASME J. Appl. Mech. 54 (1987) 1-5.

[7] K.L. Johnson, Plastic flow, residual stress and shakedown in rolling contact, in: G.M.L. Gladwell, H. Ghonem, J. Kalousek (Eds.), Proceedings of the Second International Symposium on Contact Mechanics and Wear of Rail/Wheel Systems, University of Waterloo Press, Canada, 1986, pp. 83-97.

[8] K.L. Johnson, Contact Mechanics, Cambridge University Press, Cambridge, 1985.

[9] K.L. Johnson, J.A. Jefferis, Plastic flow and residual stresses in rolling and sliding contact, in: Proceedings of the Institute of Mechanical Engineering Symposium on Rolling Contact Fatigue, London, 1963, pp. 50-61.

[10] A.F. Bower, Cyclic hardening properties of hard-drawn copper and rail steel, J. Mech. Phys. Solids 37 (4) (1989) 455-470.

[11] K. Dang Van, Introduction to fatigue analysis in mechanical design by the multi-scale approach, in: K. Dang Van, I. Papadoupoulos (Eds.), High-Cycle Metal Fatigue in the Context of Mechanical Design, CISM Courses and Lectures no. 392, Springer, Berlin, 1999, pp. $169-187$.

[12] K. Dang Van, Macro-micro approach in high cycle multi-axial fatigue, A.S.T.M. S.T.P. 1191 (1993) 120-130. 
[13] K. Dang Van, On structural integrity assessment for multi-axial loading paths, in: C.J. Beevers, A.F. Blom (Eds.), Theoretical and Concepts and Numerical Analysis of Fatigue, EMAS Ltd., UK, 1993, pp. 343-357.

[14] P. Ballard, K. Dang Van, A. Deperrois, Y. Papadopoulos, High cycle fatigue and a finite element analysis, Fatigue Fract. Eng. Mater. Struct. 18 (3) (1995) 397-411.

[15] J. Zarka, J. Frelat, G. Inglebert, P. Navidi, A New Approach to Inelastic Analysis of Structures, Martinus Nijhoff Publisher, 1989.

[16] C. Sakae, L.M. Keer, Application of a direct method for a non-linear-kinematic hardening material under rolling-sliding line contact: constant ratchetting rate, J. Mech. Phys. Solids 45 (9) (1997) $1577-1594$.

[17] C.-C. Yu, B. Moran, L.M. Keer, A simplified direct method for cyclic strain calculation: repeated rolling-sliding contact on a case hardened half space, ASME J. Tribol. 118 (1996) 329334.

[18] M. Yu, B. Moran, L.M. Keer, A direct analysis of two-dimensional elastic-plastic rolling contact, ASME J. Tribol. 115 (1993) 227236.
[19] Le The Hung, Normal und Tangential Spanningsberechnung beim Rollen den Kontakt für Rotationskörper mit Michtelliptischen Kontakt Flächen, Fortschritts Ber. VDI, 12 (1987) 87.

K. Dang Van is Doctor-es-Science of University of Paris 6, engineer of the Ecole Nationale des Ponts et Chaussées (Paris); he is actually Research Director in the CNRS (French National Center for Scientific Research); he is in charge of research in fatigue, fracture and numerical simulation of processes in the Laboratoire de Mécanique des Solides of the Ecole Polytechnique (Palaiseau, France); his fatigue multi-axial criterion is widely used. He is the chairman of the scientific committee of IDR2 (Initiative de Developpement et de Recherche sur le Rail), which includes the french railways companies, the rail manufacturers and the research organisations.

M.H. Maitournam obtained both his Engineer Degree and his PhD in the Ecole Nationale des Ponts et Chaussées (Paris); he is actually researcher in the Laboratoire de Mécanique des Solides of the Ecole Polytechnique (Palaiseau, France) and teaches at École Polytechnique; he is working in the field of numerical analysis in thermo-elastoplasticity and fatigue of structures. 